\title{
Study on Gradation Improvement of Gravel and Sand for Surface Layer of Railway Subgrade by Blending Method
}

\author{
Yang Jingwei \\ China Railway No. 2 Engineering Group Corporation Ltd., Chengdu, China \\ Email address: \\ yanken@163.com \\ To cite this article: \\ Yang Jingwei. Study on Gradation Improvement of Gravel and Sand for Surface Layer of Railway Subgrade by Blending Method. American \\ Journal of Traffic and Transportation Engineering. Vol. 4, No. 1, 2019, pp. 1-6. doi: 10.11648/j.ajtte.20190401.11
}

Received: September 26, 2018; Accepted: December 22, 2018; Published: March 25, 2019

\begin{abstract}
As the direct foundation of the track, the surface layer of high-speed railway subgrade bed is one of the important parts of the subgrade. Its main function is to transmit and spread the vertical load of the upper ballast bed and the vehicle dynamic load to maintain the long-term stability of the subgrade bed surface. So, the material for the surface layer of subgrade bed should have high strength, elastic modulus, wear resistance and invented filtration. The graded sand gravel, which is used as the filler for the surface layer of railway subgrade bed, has such features as high mechanical strength, high water stability, easy obtaining, convenient construction, low cost and so forth. The purpose of this study is to physically blend local sand gravel materials to solve the defect of excessive fine particle content, so that it can meet the grading requirements of the specification and design standards and also to provide a general calculation method and solution for the mix ratio design of natural sand gravel. In combination with a foreign project, the dissertation expatiated on the calculation method for improving the gradation defects of natural sand gravel by the blending method. Then, according to local conditions, the author successfully solved the gradation defects of natural sand gravel mixture with the said method and achieved good economic and social benefits.
\end{abstract}

Keywords: Railway Subgrade, Surface Layer of Subgrade Bed, Gravel and Sand, Gradation Improvement, Excel Solver Macro, Calculation Method

\section{Preface}

In the mix design of sand and stone mixture, a single ingredient grading is often difficult to fully meet the standard grading requirements, and two or more ingredients are usually mixed together to satisfy such grading requirements. There are two main methods for determining the mix ratio of a mixture: numerical solution and graphic solution. For the numerical solution method, the trial method and normal equation method are most commonly used. The graphic solution is mainly to plot the corrected area and calculate the solution, of which the calculation is cumbersome and should be adjusted successively. With the development of computer technology, the "Solver" macro command in Office Excel can be used to quickly and easily realize the mix design.

The graded sand gravel, which is used as the filler for the surface layer of railway subgrade bed, has such features as high mechanical strength, high water stability, easy obtaining, convenient construction, low cost and so forth. The purpose of this study is to physically blend local sand gravel materials to solve the defect of excessive fine particle content, so that it can meet the grading requirements of the specification and design standards and also to provide a general calculation method and solution for the mix ratio design of natural sand gravel $[7,8]$.

\section{Project Overview}

The Tinaco-Anaco Railway Project in the northern plain of Venezuela is totally $466.7 \mathrm{~km}$ long with the design speed of $220 \mathrm{~km} / \mathrm{h}$ under the EPC contract. The civil engineering contract section III is totally $59.0 \mathrm{~km}$ long from $\mathrm{K} 258+300$ to $\mathrm{K} 317+300$, including engineering quantities as follows: $4,970,000 \mathrm{~m}^{3}$ for excavation, $2,970,000 \mathrm{~m}^{3}$ for filling and $467,000 \mathrm{~m}^{3}$ for filling surface layer of subgrade bed, of which the quantity of the whole route is $3,700,000 \mathrm{~m}^{3}$. 


\section{Features of and Requirements for the Filler for Surface Layer}

1) As the direct foundation of the track, the surface layer of high-speed railway subgrade bed is one of the important parts of the subgrade. Its main function is to transmit and spread the vertical load of the upper ballast bed and the vehicle dynamic load to maintain the long-term stability of the subgrade bed surface. So, the material for the surface layer of subgrade bed should have high strength, elastic modulus, wear resistance and invented filtration.

2) In view of the shortage of local gravel, sand and other materials, in combination with the high-speed railway practices in Germany, France and other European countries, and based on the analysis of local geological conditions and preliminary filler investigations, it has been decided to use graded sand gravel as the filler for the surface layer of the subgrade bed instead of the graded crushed gravel proposed in the original construction plan.

3 ) If the content of fine-grained soil is too high in the grade material, the plasticity index of the aggregate may increase, the strength and rigidity may be reduced and the water stability may be deteriorated as well. The liquid limit and plasticity index of the fine aggregate in the subgrade bed surface must be strictly controlled, namely, the content of fine-grained soil smaller than $0.5 \mathrm{~mm}$ should be strictly controlled $[9,10]$.

\section{Requirements of Design Documents and Specification for Surface Layer of Subgrade Bed}

In the original design, it has been proposed that the graded crushed gravel or graded sand gravel should be used for the surface layer of the subgrade bed; if the graded sand gravel is adopted, the following technical requirements should be met[1, 2,6]:

1) Particle size and grading should meet the requirements in Table 1 .

Table 1. Gradation of Sand Gravel.

\begin{tabular}{|c|c|c|c|c|c|c|c|c|c|}
\hline \multirow{2}{*}{ No } & \multicolumn{9}{|c|}{ Percentage of mass passing through the mesh (mm) } \\
\hline & 50 & 40 & 30 & 20 & 10 & 5 & 2 & 0.5 & 0.075 \\
\hline 1 & 100 & $90 \sim 100$ & & $65 \sim 85$ & $45 \sim 70$ & $30 \sim 55$ & $15 \sim 35$ & $10 \sim 20$ & $4 \sim 10$ \\
\hline 2 & & 100 & $90 \sim 100$ & $75 \sim 95$ & $50 \sim 70$ & $30 \sim 55$ & $15 \sim 35$ & $10 \sim 20$ & $4 \sim 10$ \\
\hline 3 & & & 100 & $85 \sim 100$ & $60 \sim 80$ & $30 \sim 50$ & $15 \sim 30$ & $10 \sim 20$ & $2 \sim 8$ \\
\hline
\end{tabular}

2) The gradation curve should be close to round, and the number of particles of a certain particle size should be appropriate.

3) The number of slender and flat particles should not exceed $20 \%$ and the content of clay block and organic matter should not exceed $2 \%$.

4) $\mathrm{D}_{15}<4 d_{85}$ should be satisfied between the upper ballast bed and the lower fill.

5) The liquid limit of fine aggregates with a particle size of less than $0.5 \mathrm{~mm}$ is not greater than 25 , and the plastic limit index is not greater than 6 .

\section{Features of Local Filler}

\subsection{Results of Previous Filler Investigation}

Shortly after the investigation of the sand gravel borrow pit, the Paso Morichal Natural Sand Gravel Borrow Pit (hereinafter referred to as Borrow Pit $1^{\#}$ ) was found at about $110 \mathrm{~km}$ on the south side of the railway, of which the buried depth was more than $4 \mathrm{~m}$ and a reserve was about $400,000 \mathrm{~m}^{3}$. The Borrow Pit was located in the National Geological Park and naturally formed by crustal movement, and a large number of borrow pits could be developed nearby.

Through on-site sampling of Borrow Pit $1^{\#}$, the particle analysis test was carried out to find out the nonuniform coefficient $\mathrm{C}_{\mathrm{u}}=169.74 \geq 5$ and the curvature coefficient $\mathrm{C}_{\mathrm{c}}=11.72 \neq 1 \sim 3$, which should be of poor gradation. The grading range of Natural Sand Gravel Borrow Pit $1^{\#}$ is shown in Table 2.

\subsection{Defect of Natural Sand Gravel}

It was found through test analysis that the maximum particle size of the filler was less than $5 \mathrm{~cm}$, and could be compacted easily on the site, but some indicators did not meet the requirements, mainly in the following two aspects:

1) The plasticity index was 8.2 , which did not meet the standard requirements of plasticity index $\leq 6[1,2]$.

2) The content of fine particles was out of specification. For this filler, the content of fine particle smaller than 0.5 $\mathrm{mm}$ was more than the value provided in the specification, which was the root cause of the unsatisfactory plasticity index.

Table 2. Grading Range of Natural Sand Gravel Borrow Pit $1^{\#}$.

\begin{tabular}{|c|c|c|c|c|c|c|c|c|c|}
\hline Side length of square hole mesh (mm) & $\mathbf{5 0}$ & 40 & 30 & 20 & 10 & 5 & 2 & 0.5 & 0.075 \\
\hline Percentage of mass passing the mesh (\%) & & 100 & 98.5 & 83.3 & 54.6 & 36.7 & 26.0 & 22.8 & 13.5 \\
\hline Standard value of grading range & & 100 & $90 \sim 100$ & $75 \sim 95$ & $50 \sim 70$ & $30 \sim 55$ & $15 \sim 35$ & $10 \sim 20$ & $4 \sim 10$ \\
\hline
\end{tabular}




\section{Comparison of Improvement Schemes}

In order to make the best use of local resources and reduce the cost, appropriate improvements were carried out to make the filler meet the specification and design requirements and provide solutions for construction of the entire subgrade bed surface. From February 12 to March 5, my department performed a number of improvement tests for the material. The improvement methods mainly include:

1) Sand blending

According to unsatisfactory content of the fine particle in the filler (the content of fine particles smaller than $0.5 \mathrm{~mm}$ were out of specification), it was planned to blend the medium $\sim$ coarse sand $(425 \mathrm{um}-2 \mathrm{~mm})$ to improve the ingredients and reduce the relative content of the fine particles in the filler. However, in the actual blending test, the fine particle content and plasticity index after blending were not significantly reduced, because the ingredients of the local river sand were fine and also contained fine particles of 0.5 $\mathrm{mm}$ or less. So, this scheme was unfeasible.

2) Sieving and remixing

According to the characteristics that the natural material was slightly fine, it was carefully analyzed that the partices with the size smaller than $5 \mathrm{~mm}$ occupied $50 \%$ of the aggregate. If these particles could be removed, the half of the sieved fine ingredients were taken and then remixed according to the proportion of fine ingredient: coarse ingredient $=1: 2$, or a certain amount of stone powder (nonplastic) was added to the base material after sieving, so that the fine particle content, liquid limit and plasticity index of the blended mixture were substantially reduced.

The main difficulty of this scheme was the construction of the sieving station: First, the sieve for sieving fine ingredients should have $5 \mathrm{~mm}$ meshes as fine as the window screen. If the loader and other machines were used to directly feed the sieve on the site, the sieve should be damaged inevitably; Second, because the fine-grained material with a certain moisture content was easy to stick to the sieve, the output of the sieving operation was low and a mixing station could only produce about $500 \mathrm{~m}^{3}$ per day at the utmost, which could not meet the site demand at all; Third, the environmental assessment for field construction of the station was complicated and the sieving must be done with dry materials, which might inevitably cause great flying sand and dust during the work period and impose a greater impact on the lives and health of surrounding residents.

For the above reasons, this scheme was not operable on the site.
3) Chemical improvement with cement blending

In China, the chemical improvement method of railway subgrade filler mainly refers to the addition of cement, lime, fly ash and other admixtures to the soil. Among the others, after the various hydrates of the cement have been formed, they harden or interact with the soil to form a cement-stabilized stone frame, so that the particles are coarsened and bonded, which changes the particle composition and structure of the soil $[3,7,8]$.

According to this idea, my department started the cement blending test for the samples from February 20 and obtained the optimum blending ratio $5 \%$ when the grain coarsening effect was obvious.

However, during the discussion of the scheme at the beginning of March, the subsidiary company and the design institute did not agree on this improvement scheme, for they thought that the graded gravel must be a well-graded mixture, there was no such practice and experience in the domestic high-speed railway subgrade bed surface and the change must be reapproved by the Owner.

4) Blending of two sand gravels

Through careful analysis of the characteristics of the Natural Sand Gravel Borrow Pit $1^{\#}$ and in combination with the results of the previous tests, it was found that the fine-grained soil content of the filler could be significantly reduced and eliminated if the natural sand gravel had been washed by water or river, namely, the clayey particles with the size less than $0.075 \mathrm{~mm}$ could be eliminated, which could solve the defect of the mixture's fine and sticky properties.

Following this idea, my department energetically investigated the river sand gravel from March 5. After half a month of investigation, the Los Barraneones Borrow Pit (hereinafter referred to as Borrow Pit $2^{\#}$ ) was discovered. It was located in the drainage basin of Los Aceites River and $20 \mathrm{~km}$ far from Borrow Pit $1^{\#}$. For the Borrow Pit $2^{\#}$, the filler was well graded with a reserve of more than $300,000 \mathrm{~m}^{3}$ in the dry season, which was extremely valuable for exploitation. However, the content of fine aggregate with the size of $0.075 \mathrm{~mm}$ was less in the sand gravel ingredients of the riverbed, the sand property was obvious and the material was not easy to compact during construction.

It was relatively simple to improve this filler and only necessary to add an appropriate amount of fine-grained material at the mixing station. So, it could be mixed with the sand gravel, of Borrow Pit $1^{\#}$, which contained a large amount of fine particles, so as to meet the design requirements. The grading range of Riverbed Sand Gravel Borrow Pit $2^{\#}$ is shown in Table 3.

Table 3. Grading Range of Riverbed Sand Gravel Borrow Pit 2".

\begin{tabular}{|c|c|c|c|c|c|c|c|c|c|}
\hline Side length of square hole mesh (mm) & $\mathbf{5 0}$ & 40 & 30 & 20 & 10 & 5 & 2 & 0.5 & $\mathbf{0 . 0 7 5}$ \\
\hline Percentage of mass passing the mesh (\%) & & 100 & 98 & 90.4 & 63.8 & 42.7 & 25.3 & 17.8 & 2.5 \\
\hline Standard value of grading range & & 100 & $90 \sim 100$ & $75 \sim 95$ & $50 \sim 70$ & $30 \sim 55$ & $15 \sim 35$ & $10 \sim 20$ & $4 \sim 10$ \\
\hline
\end{tabular}

Note: The particle analysis test indicated $d_{60}=9.10, d_{30}=2.81, d_{10}=0.28$, nonuniform coefficient $\mathrm{C}_{\mathrm{u}}=32.12 \geq 5$ and curvature coefficient $\mathrm{C}_{\mathrm{c}}=3.06 \neq 1 \sim 3$, which was of poor gradation. 


\section{Gradation Calculation Method and Plasticity Index Judgment of Blending Improvement Test}

\subsection{Calculation Method of Mix Ratio of Two or More Mixtures}

If two or more fillers were mixed in a certain ratio to achieve a satisfactory gradation, the mix ratio should be determined by the numerical solution or the graphic solution.

The basic principle of the numerical solution is based on the sieving data of various aggregates and the grading range required by the specification (generally compared with the median value of the gradation), and then the mathematical regression method or computer-aided calculation method should be adopted to obtain the best ratio of the aggregates [12, $13]$.

Table 4. Passing Percentages of Aggregates.

\begin{tabular}{|c|c|c|c|c|c|c|c|}
\hline \multirow{2}{*}{$\begin{array}{l}\text { No. of Square } \\
\text { Mesh Sieve }\end{array}$} & \multicolumn{3}{|c|}{ Passing Percentages of Aggregates } & \multicolumn{3}{|c|}{ Use Level of Aggregates } & \multirow{2}{*}{$\begin{array}{l}\text { Graduation Curve } \\
\text { Median }\end{array}$} \\
\hline & 1 & 2 & $\boldsymbol{k}$ & $x_{1}$ & $x_{2}$ & $x_{\mathrm{k}}$ & \\
\hline 1 & $P_{1(1)}$ & $P_{2(1)}$ & $P_{\mathrm{k}(1)}$ & $P_{1(1)} \cdot x_{1}$ & $P_{2(1)} \cdot x_{2}$ & $P_{\mathrm{k}(1)} \cdot x_{\mathrm{k}}$ & $P_{(1)}$ \\
\hline 2 & $P_{1(2)}$ & $P_{2(2)}$ & $P_{\mathrm{k}(2)}$ & $P_{1(2)} \cdot x_{1}$ & $P_{2(1)} \cdot x_{2}$ & $P_{\mathrm{k}(2)} \cdot X_{\mathrm{k}}$ & $P_{(2)}$ \\
\hline$n$ & $P_{1(\mathrm{n})}$ & $P_{2(\mathrm{n})}$ & $P_{\mathrm{k}(\mathrm{n})}$ & $P_{1(\mathrm{n})} \cdot x_{1}$ & $P_{2(\mathrm{n})} . x_{2}$ & $P_{\mathrm{k}(\mathrm{n})} \cdot x_{\mathrm{k}}$ & $P_{(\mathrm{n})}$ \\
\hline
\end{tabular}

It was supposed that the pass rate of mineral mixture at any mesh level was $\mathrm{P}_{(\mathrm{i})}$, which was calculated by the pass rate $\mathrm{P}_{\mathrm{i}(\mathrm{j})}$ of various aggregates at this level, multiplied by the sum of the contents $x_{\mathrm{i}}$ of these aggregates in this mixture.

$$
\sum P_{i(j)} x_{i}=\mathrm{P}_{(\mathrm{i})}
$$

Where, $i$ refers to the type of aggregate, $i=1,2 \ldots \mathrm{k}$, and $j$ refers to the number of meshes, $j=1,2 \ldots n$. Then, the following equations can be listed according to the graduations in Table 4:

$$
\left\{\begin{array}{c}
\mathrm{P}_{1(1)} \cdot x_{1}+\mathrm{P}_{2(1)} \cdot x_{2}+\cdots+\mathrm{P}_{\mathrm{k}(1)} \cdot x_{\mathrm{k}}=\mathrm{P}_{(1)} \\
\mathrm{P}_{1(2)} \cdot x_{1}+\mathrm{P}_{2(2)} \cdot x_{2}+\cdots+\mathrm{P}_{\mathrm{k}(2)} \cdot x_{\mathrm{k}}=\mathrm{P}_{(2)} \\
\cdots \\
\mathrm{P}_{1(\mathrm{n})} \cdot x_{1}+\mathrm{P}_{2(\mathrm{n})} \cdot x_{2}+\cdots+\mathrm{P}_{\mathrm{k}(2)} \cdot x_{\mathrm{k}}=\mathrm{P}_{(\mathrm{n})}
\end{array}\right.
$$

The above equations can be solved by the computer-aided method or mathematical regression method.

According to this idea, the computer-aided method was adopted in this experiment, and the Excel macro command "Solver" [4] was adopted to conveniently determine the mix ratio of the materials from Borrow Pit $1^{\#}$ and $2^{\#}[11,14,16]$.

The mix ratios calculated by Excel "Solver" macro command are shown in Figure 1. The mass percentage of the $1^{\#}$ and $2^{\#}$ mixture passing through the partial meshes is shown in Table 5.

In Table 5, $x_{1}$ and $x_{2}$ are respectively the mix ratio of $\mathrm{P} 1$ and P2; the sum of the deviation values between the composite gradation corresponding to the different meshes and the median gradation of the specification is the target value of the

"Solver", namely, the minimum value. The variable cell is selected as $x_{1},\left(x_{2}=1-x_{1}\right)$. Restrictions are as follows:

1) $0 \leq x_{1} \leq 1$;

2) Gradually enter $\mathrm{P}_{1(j)} \cdot x_{1}+\mathrm{P}_{2(j)} . x_{2} \leq \mathrm{P}_{\text {upper }} ; \mathrm{P}_{\text {lower }} \leq \mathrm{P}_{1(j)} \cdot x_{1}+$ $\mathrm{P}_{2(j)} \cdot x_{2}$

After "Solution", "save" to obtain the ratio of $x_{1}$ and $x_{2}$, which should be the mix ratio of the mixture.

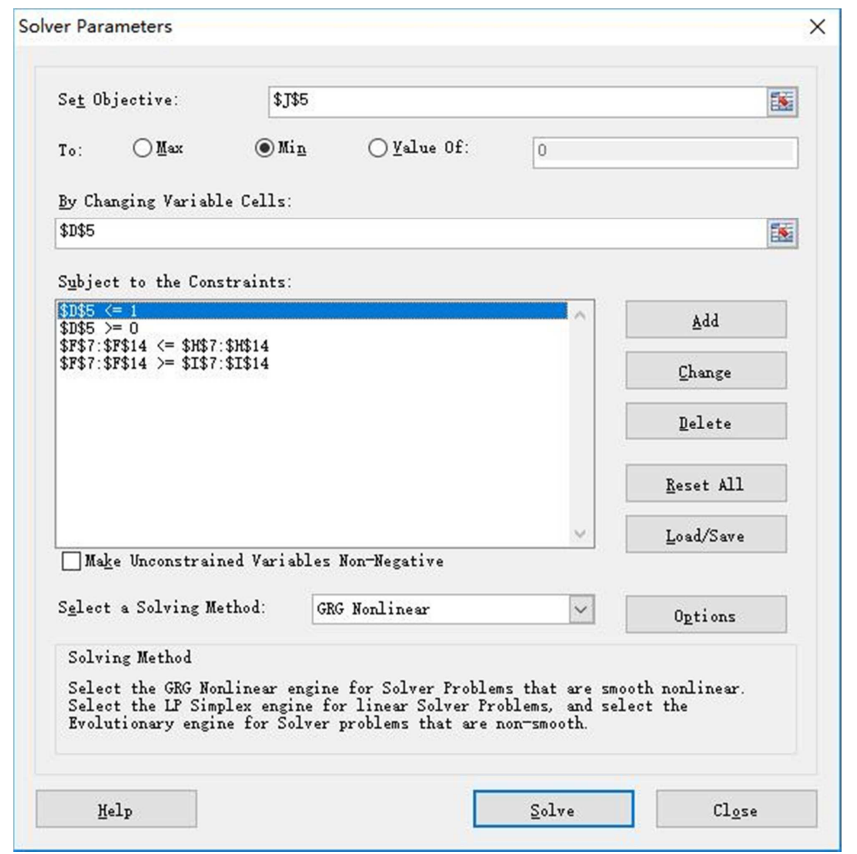

Figure 1. Mix Ratios Calculated by Excel "Solver" Macro Com.

\begin{tabular}{|c|c|c|c|c|c|c|c|c|}
\hline \multirow{2}{*}{ Mesh size / mm } & \multirow{2}{*}{$\mathbf{1}^{\#} \boldsymbol{P}_{1}$} & \multirow{2}{*}{$\mathbf{2}^{\#} \boldsymbol{P}_{2}$} & \multicolumn{2}{|c|}{ Use level of aggregate } & \multirow{2}{*}{$\begin{array}{l}\text { Composite graduation } \\
P_{1 . x_{1}}+P_{2} . x_{2}\end{array}$} & \multicolumn{3}{|c|}{ Graduation in the Specification } \\
\hline & & & $P_{1}, x_{1}$ & $P_{2} . x_{2}$ & & Median P & Upper limit & Lower limit \\
\hline 40 & 100 & 100 & 26.37 & 73.63 & 100.00 & 100 & 100 & 100 \\
\hline 30 & 98.5 & 98 & 25.97 & 72.16 & 98.13 & 95 & 100 & 90 \\
\hline 20 & 83.3 & 90.4 & 21.97 & 66.56 & 88.53 & 85 & 95 & 75 \\
\hline 10 & 54.6 & 63.8 & 14.40 & 46.98 & 61.37 & 60 & 70 & 50 \\
\hline 5 & 36.7 & 42.7 & 9.68 & 31.44 & 41.12 & 42.5 & 55 & 30 \\
\hline 2 & 26 & 25.3 & 6.86 & 18.63 & 25.48 & 25 & 35 & 15 \\
\hline 0.075 & 13.5 & 2.5 & 3.56 & 1.84 & 5.40 & 7 & 10 & 4 \\
\hline
\end{tabular}

Table 5. Mass Percentages of $1^{\#}$ and $2^{\#}$ Mixture Passing the Meshes. 
According to the results of the "Solver", the mix ratio of the materials from Borrow Pit $1^{\#}$ and $2^{\#}$ should be $0.26: 0.74$. In practice, the construction mix ratio was adjusted to 3:7 for convenience of construction. The results of the mix ratios verified as per this proportion are shown in

Table 6. Sieving Test Results after Blending Improvement of Two Kinds of Sand Gravel.

\begin{tabular}{|c|c|c|c|c|c|c|c|c|c|}
\hline Side length of square hole mesh (mm) & 50 & 40 & 30 & 20 & 10 & 5 & 2 & 0.5 & 0.075 \\
\hline Percentage of mass passing the mesh (\%) & & 100 & 98.2 & 88.6 & 65.6 & 46.1 & 28.4 & 16.4 & 6.6 \\
\hline Standard value of grading range & & 100 & $90 \sim 100$ & $75 \sim 95$ & $50 \sim 70$ & $30 \sim 55$ & $15 \sim 35$ & $10 \sim 20$ & $4 \sim 10$ \\
\hline
\end{tabular}

Note: The particle analysis test indicated $d_{60}=8.56, d_{30}=2.27, d_{10}=0.22$, nonuniform coefficient $\mathrm{C}_{\mathrm{u}}=38.50 \geq 5$ and curvature coefficient $\mathrm{C}_{\mathrm{c}}=2.71=1 \sim 3$, which was of good gradation.

\subsection{Judgment on Plasticity Index of Sandy Soil}

Due to small amount of fine particles in the mixture, the part with the size less than $0.5 \mathrm{~mm}$ was mostly sand without stickiness. The liquid and plastic limit tests could not be done by the rubbing method and stable results could not be obtained by a liquid/plastic limit tester. This problem had appeared in the test of sandy soil for many times.

According to the research results of Wang Qi, Dalian University of Technology [5], the minimum condition for the combined test method was $13 \%$ for the clay content. If the clay content was less than $13 \%$, the liquid and plastic limit tests were not necessary and it could be directly judged as sandy soil (nonplastic) according to particle analysis. Based on to this conclusion, the plasticity index could be judged to be acceptable for the clay content was less than $13 \%$ in the sieving result $[14,15]$.

\section{Paving and Compaction Effects After Improvement}

According to the mix ratio of the test, a 200m-long test section was constructed and could be well compacted by four passes on the site. The nuclear density meter and $K_{30}$ load meter were used to test the test section, respectively, and obtain the following main compaction indexes: foundation coefficient: $195 \sim 210 \mathrm{MPa} / \mathrm{m}$ and compaction coefficient $\mathrm{K}$ : 0.96 0.99. All indexes met the requirements (design requirement $\mathrm{K}_{30} \geq 190 \mathrm{MPa} / \mathrm{m}, \mathrm{K} \geq 0.95$ ), which confirmed that this blending scheme was feasible.

\section{Conclusion}

Two sand gravel fillers were mixed to well make up their respective defects, achieve the effect of "raising their strengths and avoid their weaknesses" and solve the gaps in quantity and output. Moreover, this scheme was simple in construction process and convenient for testing and inspection.

In the construction, two fillers were stored separately in the mixing stations, loaded and measured by the loader, mixed by the excavator and transported by dump trucks, so that the work efficiency was greatly improved, and the daily output could reach $4000-5000 \mathrm{~m}^{3}$. So, this scheme was a good solution to the supply of fillers.
In view of variable composition of natural gravel, multiple human factors affecting its mixing process, moisture content during the rainy season and other unfavorable factors, the testing frequency should be increased during construction. The raw materials, finished mixtures and paved subgrade materials should be sampled daily for sieving analysis, so that the fine particle content smaller than $0.5 \mathrm{~mm}$ should be strictly controlled.

After the graded sand gravel was used to replace the graded gravel and the centralized mixing process was improved, the scheme would bring great economic benefit. It was predicted that a total of 200 million US dollars would be saved for the whole route after the scheme was promoted. The test improvement scheme and construction process have been recognized by the Owner. At present, the scheme has been applied and put into practice in the whole route.

\section{References}

[1] Interim Provisions on Design of Newly-built 200-250km Passenger Dedicated Railways [S]. TJS [2005] No. 140, China Railway Publishing House, 2009. Beijing.

[2] Code for Soil Test of Railway Engineering [S]. TB10102-2004, China Railway Publishing House, 2004. Beijing.

[3] Wu Lianhai, Song Yongjun. Compaction Testing and Time Effect of the Cement-mixed Soil Subgrade Bed for Passenger Railway Line [J]. Railway Investigation and Surveying, 2005, (1): 33-35.

[4] Yang Huiguang, Optimized Calculation of Bitumen Mix Design by Excel [J]. Journal of Highway and Transportation Research and Development, 2000, 17 (5): 13-14.

[5] Wang Qi, Study on Determination of Liquid and Plastic Limits of Fine-Grained Soil By Joint Determination Method [D]. Master's Thesis of Dalian University of Technology, June 2008.

[6] Wu Youming, Study on Filled Soil Classification and Compaction Standard of Railway Subgrade [D]. Master's Thesis of Southwest Jiao-Tong University of Technology, Dec 2004.

[7] Qian Lixing, The Word High-Speed Railway Technology [M]. Beijing: China Railway Publishing House.

[8] Yang Guangqing, The Construction and Design of High-Speed Railway Embankment [M]. Beijing: China Railway Publishing House. 
[9] Zhang Zhengang, The Subgrade Bed Research of the High-Speed Railway [J]. China Safety Science Journal, Volume 06, 2002

[10] Yan Shengen, The Subgrade Bed Design of The High-Speed Railway [J]. The Subgrade Construction, Volume 3, 1997.

[11] Mei Yingjun, The Nonlinear Analysis of Aggregate [J]. Journal of Chong-Qin Jiao-Tong University, Volume 3, 2004.

[12] Chai Hejun, Overview of Soil-Stone High Embankment Construction Study [J]; Rock and Soil Mechanics, Jun 2004.

[13] Chai He-Jun, Research on Grain Size Features an Fractal Dimensions of Soil-Stone Mixed Materials [J]. Technology of Highway and Transport, Dec 2009.

[14] Kong Xiangchen, Experiment and Research on Vibrating Compaction Properties of Soil-Aggregate Mixture [J]. Chinese Journal of Undergrad Space and Engineering.

[15] Liang Xiangqian. Experimental Study on Vibrating Compaction Performance of Gravel Soil [J]. Chinese Journal of Rock Mechanics and Engineering, Aug. 2005.
[16] Tang Shuguang, Study on How to Use the Least Square Method in the Analysis of Experimental Data [J], Dec. 2003.

\section{Biography}

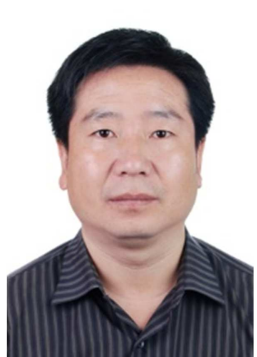

Yang Jingwei is born in April 1974. Graduated from Southwest Jiaotong University Civil Engineering Institute. Bachelor Degree. Senior Engineer. Working in China Railway No.2 Engineering Co. Ltd. (CREGC), China. Mainly engaged in the technical management and theoretical research of overseas engineering projects. Participated in project construction in Laos, Vietnam, Venezuela and other countries, has nearly 20 years of overseas construction management experience involving railway, highway, municipal and other fields. There are more practice and research results in classification of subgrade filling and site test. 